\title{
Design and Characterization of an Ocular Topical Liposomal Preparation to Replenish the Lipids of the Tear Film
}

\author{
Marta Vicario-de-la-Torre, ${ }^{1,2}$ José Manuel Benítez-del-Castillo, ${ }^{2,3}$ Eva Vico, ${ }^{3}$ Manuel Guzmán, ${ }^{4}$ \\ Beatriz de-las-Heras, ${ }^{5}$ Rocío Herrero-Vanrell, ${ }^{1,2}$ and Irene T. Molina-Martínez ${ }^{1,2}$ \\ ${ }^{1}$ Department of Pharmacy and Pharmaceutical Technology, Faculty of Pharmacy, Complutense University of Madrid, Madrid, Spain \\ ${ }^{2}$ Pharmaceutical Innovation in Ophthalmology Research Group, Sanitary Research Institute of the San Carlos Clinical Hospital \\ (IdISSC) and the Ocular Pathology National Net (OFTARED) of the Institute of Health Carlos III, Madrid, Spain \\ ${ }^{3}$ Ocular Surface and Inflammation, Ophthalmology Department, San Carlos Clinical Hospital, Madrid, Spain \\ ${ }^{4}$ Department of Pharmacy and Pharmaceutical Technology, Faculty of Pharmacy, University of Alcalá de Henares, Alcalá de Henares, \\ Madrid, Spain \\ ${ }^{5}$ Department of Pharmacology, Faculty of Pharmacy, Complutense University, Madrid, Spain
}

Correspondence: Irene T. MolinaMartínez, Department of Pharmacy and Pharmaceutical Technology, Faculty of Pharmacy, Complutense University, Plaza Ramón y Cajal s/n, 28040 Madrid, Spain;

iremm@farm.ucm.es.

Submitted: April 30, 2014

Accepted: October 20, 2014

Citation: Vicario-de-la-Torre M, Benítez-del-Castillo JM, Vico E, et al. Design and characterization of an ocular topical liposomal preparation to replenish the lipids of the tear film. Invest Ophthalmol Vis Sci. 2014;55:7839-7847. DOI:10.1167/ iovs. $14-14700$
Purpose. Dry eye (DE) includes a group of diseases related to tear film disorders. Current trends for DE therapy focus on providing lipid components to replace the damaged lipid layer. Formulations that contain aqueous and mucin-like compounds may have additional therapeutic benefits for DE patients. The aim of this work was to design and evaluate novel formulations having the potential to become topical treatment for DE.

Methons. Unpreserved liposomal formulations composed of phosphatidylcholine (PC), cholesterol, and $\alpha$-tocopherol (vit E) were prepared by the thin-film hydration technique. Formulations were characterized in terms of liposome size, $\mathrm{pH}$, surface tension, osmolarity, and viscosity. In vitro tolerance assays were performed on macrophage, human corneal, and conjunctival cell lines at short- and long-term exposures. In vivo ocular tolerance was studied after instillation of the formulation.

Results. The mean liposome size was less than $1 \mu \mathrm{m}$ and surface tension $<30 \mathrm{mN} / \mathrm{m}$ for all formulations. The final liposomal formulation (PC-cholesterol-vit $\mathrm{E}$ in a ratio of 8:1:0.8) had physiological values of $\mathrm{pH}(6.45 \pm 0.09)$, osmolarity $(289.43 \pm 3.28 \mathrm{mOsm})$, and viscosity $(1.82 \pm 0.02 \mathrm{mPa} \cdot \mathrm{s})$. Cell viability was greater than $80 \%$ in the corneal and conjunctival cells. This formulation was well tolerated by experimental animals.

Conclusions. The unpreserved liposomal formulation has suitable properties to be administered by a topical ophthalmic route. The liposome-based artificial tear had good in vitro and in vivo tolerance responses. This formulation, composed of a combination of liposomes and bioadhesive polymers, may be used successfully as a tear film substitute in DE therapy.

Keywords: liposomes, nanotechnology, dry eye
$T$ he ocular surface (OS) is the interface between the eye and external environment. In the healthy state, the OS maintains a homeostatic balance that ensures sharp images. The tear film covers the OS and fulfills important functions, such as refraction, achieving optimal environmental conditions for the cells of the cornea and conjunctiva, lubricating the eyelids to facilitate the act of blinking, transporting metabolites (mainly $\mathrm{O}_{2}$ and $\mathrm{CO}_{2}$ ), and the dilution and removal of harmful elements. $^{1}$

Recent studies suggest that the tear film is composed of an outer lipid layer and a hydrated gel that includes aqueous components, such as electrolytes, proteins, and mucins, forming a decreasing gradient of mucin concentration from the OS to the air interface., ${ }^{2,3}$ Meibum and tear film lipids, composed mainly of cholesterol esters, wax esters, fatty acids, and phospholipids, are physiologically important with functions that are well described. ${ }^{4-8}$ The phospholipid fraction represents approximately 5\% to $15 \%$ of the total lipid component of the tear film, of which approximately $40 \%$ is phosphatidylcholine (PC) and $18 \%$ is phosphatidylethanolamine. ${ }^{4}$

Two models describe the molecular organization of the tear film lipid layer. McCulley and Shine ${ }^{9}$ described a double-layered lipid film. The first layer is in contact with the mucinousaqueous film and is composed of a polar lipid phase containing mucins, phospholipids, sphingomyelin, ceramides, and cerebrosides. The second one is a nonpolar hydrophobic phase composed mainly by wax esters, cholesterol esters, triglycerides, free fatty acids, and hydrocarbons. This nonpolar lipid film is in direct contact with the external atmosphere.? More recently, Fuller et al. ${ }^{10}$ suggested a model of the tear film lipid layer that is composed of a continuous liquid phase with solid lamellar particles in suspension. In this model, the polar lipids are adsorbed with proteins and are found properly oriented in 
the aqueous/lipid interface according to their amphiphilic properties.

The lipid layer of the tear film participates in preventing $90 \%$ to $95 \%$ of water evaporation, promoting the extension of the tear film on the OS after blinking, and contributing to the viscoelastic properties of the tear film. ${ }^{11-13}$ Moreover, recent studies have highlighted the role of meibomian lipids in enhancing tear film stability and water evaporation. ${ }^{14-17}$

Mucins form part of the hydrated gel and contain the aqueous components of the tear film. Mucins stabilize tear film, eliminate waste substances, and promote the lubrication of the OS. The aqueous components of tears regulate $\mathrm{pH}$, osmolarity, and the integrity of the corneal and conjunctival epithelia.

When designing a topical ocular formulation, it is crucial to take into account the physiological and physicochemical properties of the different constituents that form the tears. The composition of a topically applied preparation that supplements the tear film should be similar to the components that are naturally produced by the eye and the adnexa. Such a formulation should simulate the natural tear film characteristics. The aim of this work focused on the design, preparation, characterization, and tolerance evaluation of a topically administered ophthalmic liposomal formulation that is capable of promoting the replenishment of the destabilized tear film. According to the composition of natural tears, this formulation must consist of hydrophobic lipids; amphiphilic lipids; electrolytes that maintain $\mathrm{pH}$ and isotonicity; and mucin-like compounds that provide suitable viscosity, enable gel formation, and interact with the epithelial cell mucins to increase the retention time on the OS. Importantly, this formulation must not have preservatives, like benzalkonium chloride (BAK), that can damage the OS, especially in patients requiring long-term treatments. ${ }^{18-20}$

\section{Materials AND Methods}

\section{Compounds}

The following materials were used in this study: Soy lecithin PC (Phospholipon 90G; Lipoid GmbH, Ludwigshafen, Germany); cholesterol, $\alpha$-tocopherol (vit E), tetrazolium salt 3(4,5-dimethylthiazol-2-yl)-2,5-diphenyltetrazolium bromide (MTT), dimethyl sulfoxide (DMSO), and BAK (from Sigma Aldrich Química S.L., Madrid, Spain); chloroform (Panreac Química S.A., Madrid, Spain); and sodium hyaluronate ( $\mathrm{SH}$, ophthalmic grade NaHa, 400,000-800,000 Da molecular weight; Abaran Materias Primas S.L., Madrid, Spain). All culture reagents were purchased from Gibco-Invitrogen (Life Technologies, Barcelona, Spain). Male New Zealand white rabbits, 2.0 to $2.5 \mathrm{~kg}$, were purchased from San Bernardo Farm (Navarra, Spain).

\section{Liposome Preparation}

Liposomal formulations were prepared by the thin-film hydration method. ${ }^{21}$ The lipid components, PC, cholesterol, and vit $\mathrm{E}$ were first solubilized in chloroform in a concentration ratio 8:1:0.08 $(\mathrm{mg} / \mathrm{mL})$. Then, the organic solution was evaporated in a rotary evaporator (Buchi R-205; Massó Analítica S.A., Barcelona, Spain) at $33^{\circ} \mathrm{C}$, forming a thin lipid film on the inside of a round bottom evaporator flask. This film was first redispersed in purified water (Milli Q Elix 3 and gradient A10; Millipore, Madrid, Spain) to yield the aqueous liposomal dispersion. The dispersion was left undisturbed at room temperature for 2 hours to allow complete swelling of the lipid film. After that, liposomes were sonicated to form smaller vesicles and make the extrusion process that followed easier. The influence of the sonication process on liposomes was
TABLE 1. Formulation Nomenclature and Composition

\begin{tabular}{lcc}
\hline Formulation & \multicolumn{1}{c}{ Composition } & Polymer \\
\hline F1 & PC $20 \mathrm{mg} / \mathrm{mL}$ and water & - \\
F2 & PC $20 \mathrm{mg} / \mathrm{mL}$ and $0.9 \% \mathrm{NaCl}$ & - \\
F3 & PC $10 \mathrm{mg} / \mathrm{mL}$ and $0.9 \% \mathrm{NaCl}$ & $0.2 \% \mathrm{SH}$ \\
\hline
\end{tabular}

studied by using either a probe sonicator (Sonicator XL; Heat Systems, Misonix, IA, USA) for 2.5 minutes or an ultrasound bath (Ultrasons-H, Madrid, Spain) for 15 minutes. To optimize the manufacturing technique after sonication with the probe sonicator, the influence of the extrusion process was studied. To standardize the size and structure of the formed vesicles, liposomes were passed through $800-\mathrm{nm}$ pore size membranes (FilterLab, Barcelona, Spain) from 1 to 5 cycles.

Once the liposome manufacturing process was optimized in terms of the sonication device and cycles of extrusion, the dried thin lipid films were dispersed in MilliQ water to produce liposome formulation, named as $\mathrm{F} 1$, or in $0.9 \% \mathrm{NaCl}$ to produce liposome formulation F2. Formulation F3 was prepared from F2 by a dilution (1:2) in an isotonic solution of $\mathrm{SH}$. The nomenclature and composition of the formulations are listed in Table 1.

\section{Size Determinations}

The assessment of the liposome sizes was done by photon correlation spectroscopy using a Nanosizer N4 (Beckman Coulter, Madrid, Spain). Determining the liposome size was done with the aqueous liposomal dispersion. All measurements were made at least in duplicate.

\section{Analysis of Surface Tension}

The surface tension was determined by a tensiometer (model K-11; Krüss GmbH, Hamburg, Germany) using the Wilhelmy plate method. ${ }^{22,23}$ The measurements were performed at $33^{\circ} \mathrm{C}$, which corresponds to the OS temperature. ${ }^{24}$ The tensiometer was calibrated with purified water before determining the surface tension of the liposomal dispersions. The surface tension of the water was 68 to $72 \mathrm{mN} / \mathrm{m}$. The measurements were made in triplicate on three different batches of liposomes.

\section{Assessment of the PC Concentration in the Liposome Formulations}

The PC concentration in the liposomal formulations was determined by colorimetric titration using the Spinreact kit (Spinreact SA, Gerona, Spain) and read at $505 \mathrm{~nm}$ using a Beckman DU-7 spectrometer (Beckman Coulter). Linearity, accuracy, and precision of the output were validated using PC concentrations ranging from 0.05 to $4 \mathrm{mg} / \mathrm{mL}$. Before assay, the PC standards and samples were dispersed in water by magnetic stirring and sonication in an ultrasonic bath. Measurements were made in triplicate for three different batches of liposomes.

\section{Determination of $\mathbf{p H}$, Osmolarity, and Viscosity}

The $\mathrm{pH}$, osmolarity, and viscosity of the dispersions also were measured. The $\mathrm{pH}$ was determined at $25^{\circ} \mathrm{C}$ by a calibrated $\mathrm{pH}$ meter (Mettler, Toledo, Spain). The osmolarity was measured with a Knauer vapor osmometer K-7000 (Knauer GmbH, Berlin, Germany). For reference we used a standard $400 \mathrm{mOsm}$ solution of sodium chloride. Determinations were performed 
at $33^{\circ} \mathrm{C}$ corresponding to OS temperature. Sample viscosities were determined with a rheometer (HaakeRheostress R1; Haake, Düsseldorf, Germany) using parallel plate geometry (diameter $60 \mathrm{~mm}$, gap $0.5 \mathrm{~mm}$ ). The viscosity was calculated at $33^{\circ} \mathrm{C}$ by the steady state flow method. ${ }^{25,26}$ The shear rate was increased gradually in 20 steps from 0 to $1000 \mathrm{~s}^{-1}$. In all cases, determinations were made in triplicate.

\section{In Vitro Tolerance Studies}

In vitro tolerance assays were determined by cellular viability measurements in the following cell lines: (1) mouse macrophage cell line RAW 264.7 was obtained from ATCC (Barcelona, Spain) (2) immortalized human corneal-limbal epithelial cells (HCLE, kindly provided by Ilene K. Gipson; Schepens Eye Research Institute, Harvard Medical School, Boston, MA, USA), and (3) normal human conjunctiva cells (IOBA-NHC; Instituto de Oftalmobiología Aplicada, Valladolid University, Valladolid, Spain). ${ }^{27}$ The RAW 264.7 macrophages were maintained in RPMI 1640 medium supplemented with $10 \%$ fetal bovine serum, L-glutamine $(1 \mathrm{mM})$, penicillin (100 U/ $\mathrm{mL})$, and streptomycin $(100 \mu \mathrm{g} / \mathrm{mL})$ at $37^{\circ} \mathrm{C}$ in a humidified $5 \%$ $\mathrm{CO}_{2}$ atmosphere, as described previously. ${ }^{28}$ The HCLE and IOBA-NHC cell lines were cultured according the protocol described previously by Andres-Guerrero et al. ${ }^{29}$

Cytotoxicity assays were done by the mitochondrialdependent reduction of the tetrazolium salt MTT to formazan. ${ }^{30,31}$ Cells were seeded into 96-well culture plates $(50,000$ cells/well for macrophage cell line and 40,000 cells/well for corneal and conjunctival cells). After the cells adhered to the plates, the culture medium was removed and the test vehicle or liposome formulation was added. ${ }^{32}$ The exposure times of cells to formulations was set at 15 minutes to simulate shortterm exposures, and at 1 and 4 hours to simulate longer term chronic treatments. The RAW 264.7 macrophages then were incubated for 1 hour, and the HCLE and IOBA-NHC cells were incubated for 3 hours with the MTT solution $(5 \mathrm{mg} / \mathrm{mL}$ in PBS). After that, the medium was carefully aspirated, and the cells were solubilized in DMSO $(100 \mu \mathrm{L} /$ well $)$. The extent of the reduction of MTT to formazan was measured by optical density at $550 \mathrm{~nm}$ using a plate reader (model 6010152EU; Digiscan, Eugendorf, Austria).

Viability was set as $100 \%$ in untreated cells (negative control). The positive control was an isotonic solution of $0.005 \%$ BAK that produces cellular death. ${ }^{33,34}$ Assays were performed in triplicate and results are expressed as the reduction in cell viability compared to untreated cells for at least three independent experiments.

\section{Animals}

Male New Zealand white rabbits weighing between 2 and 2.5 $\mathrm{kg}$ were caged individually with free access to food and drink. The room was maintained at $22^{\circ} \mathrm{C}$ and $50 \%$ relative humidity, and had a 12-hour light/dark cycle. The tests performed were compliant with the ARVO Statement for the Use of Animals in Ophthalmology and Vision Research, and the corresponding directive of the European Community (European Communities Council Directive 86/609/EEC).

\section{In Vivo Tolerance Study}

The in vivo tolerance study was done on six rabbits. The liposomal formulation selected was administered in the ocular cul-de-sac. We administered $30 \mu \mathrm{L}$ of the formulation in the right eye and the same volume of $0.9 \% \mathrm{NaCl}$ solution in the contralateral eye as the control. The administration was performed every 30 minutes for 6 hours. Clinical symptoms and signs were evaluated in accordance with a previously described protocol. ${ }^{35}$ The OS evaluation was made before the first instillation, and at 3, 6, and 24 hours after the first administration. Macroscopic examination of the in vivo tolerance was graded from 0 to 2 , indicating the absence or presence of the following clinical signs: loss of corneal transparency, conjunctival disorders (hyperemia, edema), eyelid swelling, and intense blinking that indicated a lack of tolerance.

\section{Statistical Analysis}

Data were expressed as means \pm SDs. Overall effects were determined by analysis of variance. If necessary, statistical differences between two mean values were analyzed by 2 tailed Student's $t$-test. Results were considered as significantly different at $P<0.05$. Data plotting and line fitting were carried out by Origin Pro-8 (Originlab, Northampton, MA, USA).

\section{Results}

\section{Effect of Preparation Method on the Size of Lipid Vesicles}

We optimized the method for preparation of the liposomes by evaluating two sonication devices. Our goal was to achieve liposomes with the best uniformity of size to avoid liposomal aggregation and maintain vesicles of stable diameter.

To optimize the preparation method, we used two approaches: the influence of the sonication process and the number of extrusion cycles through the polycarbonate membranes. As described previously, after determining the optimal sonication method and number of extrusion cycles, two liposomal formulations were obtained by using different redispersion solutions (Table 1): Liposomes in formulation F1 were dispersed with water, meanwhile liposomes in formulation $\mathrm{F} 2$ were dispersed with $0.9 \% \mathrm{NaCl}$. The nominal liposome lipid concentration after sonication and extrusion, expressed as the PC concentration, was $20 \mathrm{mg} / \mathrm{mL}$. Finally, a third formulation, F3, was obtained after diluting F2 (1:2) with a solution of $\mathrm{SH}$ in $0.9 \% \mathrm{NaCl}$. The $\mathrm{F} 3$ formulation had $\mathrm{PC}$ and $\mathrm{SH}$ concentrations of $10 \mathrm{mg} / \mathrm{mL}$ and $0.2 \%$, respectively.

We determined the effects of the number of extrusion cycles and the sonication method on vesicle size using an aqueous liposomal dispersion. To select the number of extrusion cycles, we first used the ultrasonication probe for 2.5 minutes. The size distribution of the lipid vesicles was affected by the number of extrusion cycles through the polycarbonate filter (Figs. 1A-C). In these conditions, the average vesicle diameter decreased with increasing number of extrusion cycles (Table 2). At the maximum extrusion of five cycles, less than $3 \%$ of the vesicles had diameters of more than $1 \mu \mathrm{m}$. Thus, by increasing the number of extrusion cycles, a greater uniformity of liposome size was achieved, and after five cycles the distribution was bimodal (Fig. 1C).

After selecting five extrusion cycles as optimal to achieve the best uniformity of size, we determined the effects of the sonication devices used in the preparation of liposomes. The effects on liposomal dispersion by the ultrasonic probe (2.5 minutes) and the ultrasonic bath (15 minutes) were compared. The frequency distribution for vesicle size was bimodal for both sonication methods (Fig. 2). The sonication probe produced a much higher frequency of vesicles that were less than $0.1 \mu \mathrm{m}$ in diameter, but the sonication bath procedure yielded higher uniformity of liposome size. The high uniformity of size reduces aggregation and improves colloidal stability of the system. ${ }^{36,37}$ Therefore, formulations F1, F2, and F3 were 


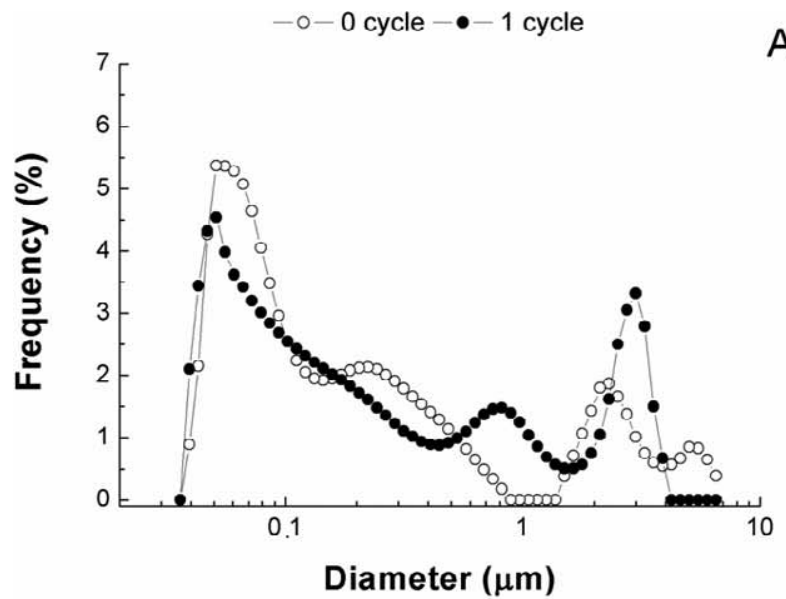

A

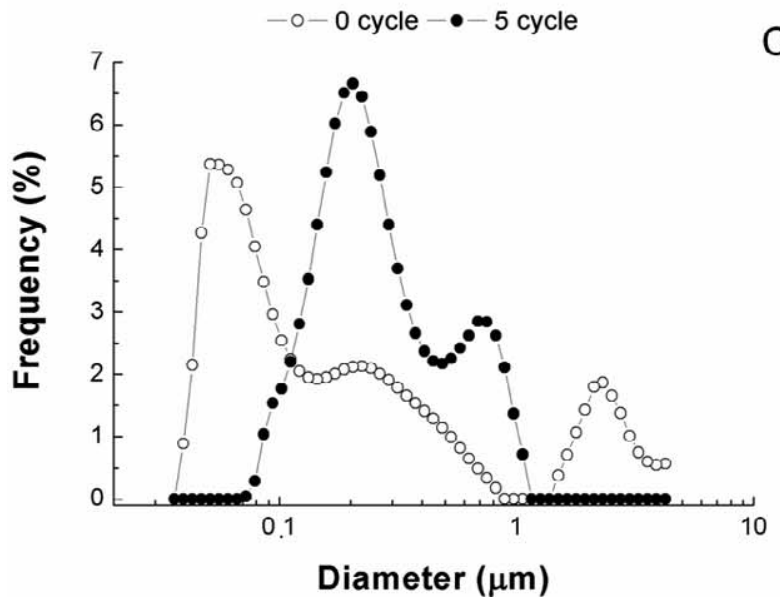

$\mathrm{C}$

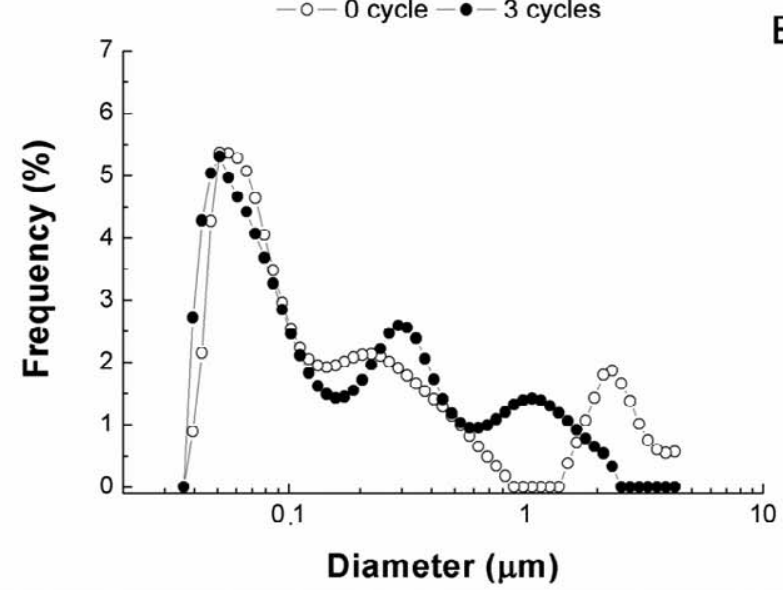

Figure 1. Size distribution of lipid vesicles obtained with (A) one, (B) three, and (C) five cycles of extrusion. $\bigcirc$, liposome dispersion with 0 extrusion cycles; $\mathbf{O}$, liposome dispersion subjected to one $(\mathbf{A})$, three $(\mathbf{B})$, and five $(\mathbf{C})$ extrusion cycles.

subjected to sonication by ultrasound bath and after that to five extrusion cycles.

\section{The Influence of Liposome Concentration on the Surface Tension}

Using PC as a measure of liposome concentration, we studied the effect of liposome concentration on surface tension. To do this, different liposomal concentrations were prepared by diluting F1 and F2 formulations from 25.6 to $1 \times 10^{-6} \mathrm{mM}$. From concentrations of $1 \times 10^{-6}$ to $1.02 \times 10^{-2} \mathrm{mM}$, the surface tension of both formulations was quite similar to water (Fig. 3). For both formulations, there was a decrease in surface tension at $0.102 \mathrm{mM}$, which corresponded to the PC concentration at which the liposomes became visible by light

TABLE 2. Effect of Extrusion Cycles on Liposome Diameter

\begin{tabular}{lcc}
\hline Extrusion Cycles & VD, $\mathbf{n m}$ & $\boldsymbol{F}_{\boldsymbol{\emptyset}}>\mathbf{1} \boldsymbol{\mu \mathbf { m }}, \boldsymbol{\%}$ \\
\hline 0 & 710 & 20.0 \\
1 & 712 & 18.5 \\
3 & 389 & 6.3 \\
5 & 269 & 2.7 \\
\hline
\end{tabular}

Liposomes were prepared with PC, cholesterol, and vit E in water, and sonicated with a probe for 2.5 minutes. VD, vesicle diameter; $F_{\varnothing}>$ $1 \mu \mathrm{m}$, percentage of vesicles with a size greater than $1 \mu \mathrm{m}$. microscopy. At $25 \mathrm{mM}$ PC (equivalent to $20 \mathrm{mg} / \mathrm{mL}$ ) the surface tension decreased to approximately $30 \mathrm{mN} / \mathrm{m}$.

\section{Assessment of the Amount of PC in Liposomes}

The yield during liposome formation was determined on the F1 formulation with an initial PC concentration of $20 \mathrm{mg} / \mathrm{mL}$. The

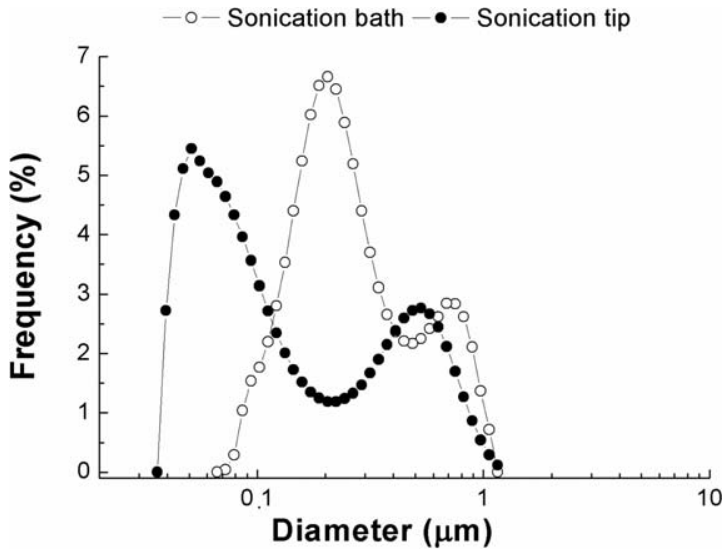

FIGURE 2. Effect of sonication devices on liposome size distribution. $\bigcirc$, liposome dispersion by ultrasonic bath;, liposome dispersion by sonication tip. 


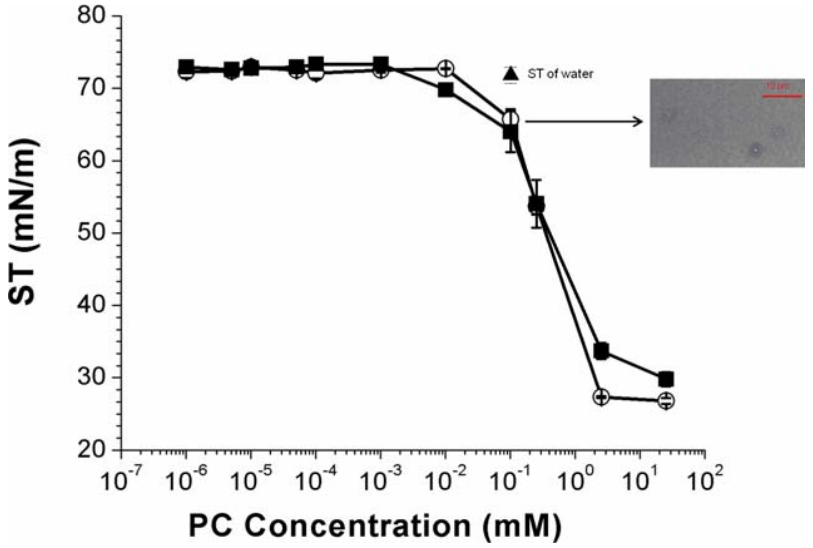

Figure 3. Concentration-dependent surface tension (ST) of liposome formulations. Liposomes in water $(\mathrm{F} 1, \mathrm{O})$ and liposomes in $0.9 \% \mathrm{NaCl}$ (F2, a). At $0.102 \mathrm{mM} \mathrm{PC} \mathrm{(arrow)} \mathrm{the} \mathrm{liposomes} \mathrm{in} \mathrm{both} \mathrm{formulations}$ became visible by light microscopy (see micrograph inserted in graph). $\mathbf{\Delta}$, surface tension of water (reference).

PC concentrations were quantified in three key stages of liposome preparation: unfiltered liposomes or multilamellar vesicles, liposomes after sonication by ultrasonic bath, and liposomes after five extrusion cycles. The PC concentrations in any of the steps of the preparation were not significantly different from the theoretical $20 \mathrm{mg} / \mathrm{mL}$ (Table 3).

\section{Determination of $\mathbf{p H}$, Osmolarity, and Viscosity}

The $\mathrm{pH}$, osmolarity, and viscosity were measured for all formulations and corresponding vehicles (Table 4). The $\mathrm{pH}$ values of the liposomal formulations F1 to F3 were between 6.5 and 6.7 , and were significantly greater than the pHs of the two vehicles $(P<0.001)$.

The osmolarity of the F1 preparation was not significantly different from zero (Table 4). Although significant differences in osmolarity were present among the liposomal formulations and vehicles, the osmolarity values obtained for $\mathrm{F} 2$ and $\mathrm{F} 3$ were in the range of iso-osmolarity.

The viscosity and rheological properties of all of the samples closely followed Newtonian behavior (Fig. 4). With the exception of isotonic $0.9 \% \mathrm{NaCl}$, the viscosities of the samples were higher than the viscosity of water. The slight increase in viscosity induced by the liposomes, $<0.1 \mathrm{mPa} \cdot \mathrm{s}$, was physiologically insignificant (Table 4). The final proposed formulation $\mathrm{F} 3$ had a viscosity similar to that of human tears, 0.3 to $8.3 \mathrm{mPa} \cdot \mathrm{s}^{38,39}$

\section{In Vitro Tolerance Studies}

Cell viability was measured in the presence of formulations F2, $\mathrm{F} 3$, and the respective vehicles in short-, intermediate-, and long-term exposures in RAW 264.7 macrophage, HCLE, and

TABLE 3. Experimentally Determined PC Concentration

\begin{tabular}{lcc}
\hline \multicolumn{1}{c}{ Stage } & PC Concentration, $\mathbf{~ m g / m L}$ & $\boldsymbol{P}$ \\
\hline MLV liposomes & $19.4 \pm 0.5$ & 0.166 \\
After ultrasonication & $19.1 \pm 0.5$ & 0.088 \\
After 5 extrusion cycles & $18.8 \pm 0.5$ & 0.053
\end{tabular}

The PC concentration at different stages of liposome preparation in water $(n=3)$. MLV, multilamelar vesicles; $P$, probability that the experimentally determined PC concentration was significantly different from the theoretical concentration of $20 \mathrm{mg} / \mathrm{mL}$.
TABLE 4. Vehicle and Liposome Formulation $\mathrm{pH}$, Osmolarity, and Viscosity

\begin{tabular}{lccc}
\hline \multicolumn{1}{c}{ Sample } & pH & $\begin{array}{c}\text { Osmolarity, } \\
\text { mOsm }\end{array}$ & $\begin{array}{c}\text { Viscosity, } \\
\text { mPa.s }\end{array}$ \\
\hline $0.9 \% \mathrm{NaCl}$ & $5.55 \pm 0.02$ & $297.07 \pm 7.91$ & $0.78 \pm 0.01$ \\
$0.2 \% \mathrm{SH}-0.9 \% \mathrm{NaCl}$ & $5.58 \pm 0.02$ & $301.20 \pm 1.10$ & $1.75 \pm 0.02$ \\
F1 & $6.67 \pm 0.01$ & $-2.31 \pm 1.53^{*}$ & $0.91 \pm 0.01$ \\
F2 & $6.61 \pm 0.03$ & $279.10 \pm 3.00$ & $0.97 \pm 0.06$ \\
F3 & $6.45 \pm 0.09$ & $289.43 \pm 3.28$ & $1.82 \pm 0.02$ \\
\hline
\end{tabular}

Vehicle for $\mathrm{F} 1$ was $\mathrm{H}_{2} \mathrm{O}$ (data not shown). Vehicle for $\mathrm{F} 2$ was $0.9 \%$ $\mathrm{NaCl}$. Vehicle for $\mathrm{F} 3$ was $0.2 \%$ sodium hyaluronate (SH)- $0.9 \% \mathrm{NaCl}$. F1, liposomes dispersed with water; F2, liposomes dispersed with $0.9 \%$ $\mathrm{NaCl}$; F3, liposomes dispersed with $0.2 \% \mathrm{SH}-0.9 \% \mathrm{NaCl}$.

* Value associated with the osmometer measurement variations, not significantly different from distilled water.

IOBA-NHC cell lines (Fig. 5). The macrophages were more sensitive to the test solutions than were either of the OSderived lines (Fig. 5A versus Figs. 5B, 5C). The RAW macrophages had the lowest cell viability values, $<20 \%$, for the positive control, $0.005 \%$ BAK, after short-, intermediate-, and long-term exposures, while these values were between $20 \%$ and $40 \%$ for HCLE and IOBA-NHC cells.

After exposures of 15 minutes and 1 hour to formulations F2 and F3, macrophage viability was greater than $80 \%$ (Fig. 5A). For the HCLE (Fig. 5B) and IOBA-NHC (Fig. 5C) cells, viabilities were higher than $95 \%$ for the F2 and F3 formulations at 15 minutes, and 1 and 4 hours.

\section{In Vivo Tolerance Studies}

Before testing, all animals $(n=6)$ had a normal OS and corneal transparency. None had any conjunctival disorders, including hyperemia or edema, eyelid swelling, or intense blinking (grade 0 ). The animals showed no discomfort during the test or within 24 hours after the administration of formulation F3, which contained $0.2 \% \mathrm{SH}-0.9 \% \mathrm{NaCl}$. The cornea remained transparent (no vessels) throughout the assay (grade 0 ) and the coloration of the conjunctiva remained normal except for one rabbit with a slight hyperemia observed at 6 hours after the first instillation (grades 0-1). This hyperemia was transient and disappeared by the end of the study ( 24 hours). No animal

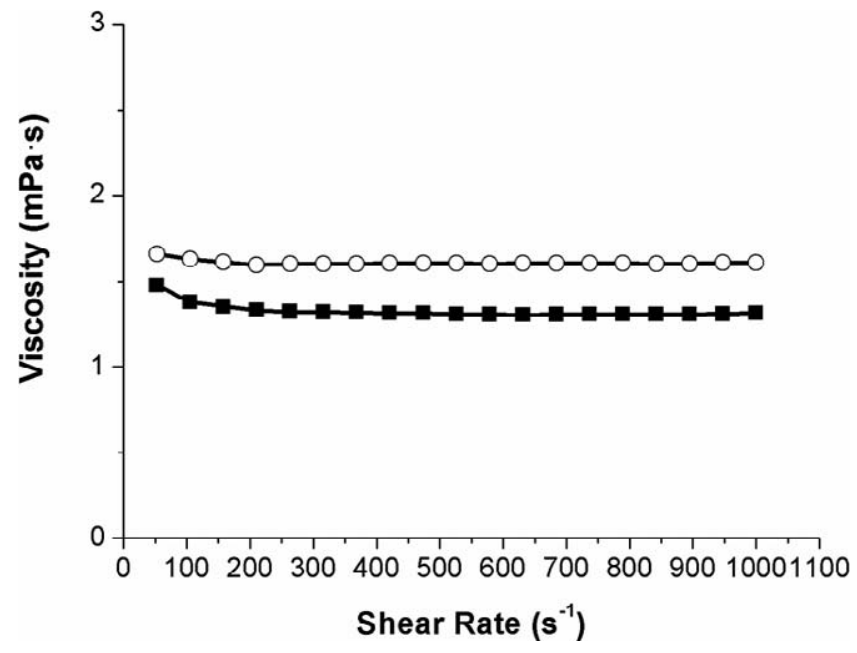

Figure 4. Viscosity profiles of $0.2 \% \mathrm{SH}-0.9 \% \mathrm{NaCl}$ and $\mathrm{F} 3$. $-0.2 \%$ $\mathrm{SH}-0.9 \% \mathrm{NaCl}$ (an isotonic formulation of sodium hyaluronate); $\mathrm{O}, \mathrm{F} 3$ liposome formulation dispersed in $0.2 \% \mathrm{SH}-0.9 \% \mathrm{NaCl}$. 
A

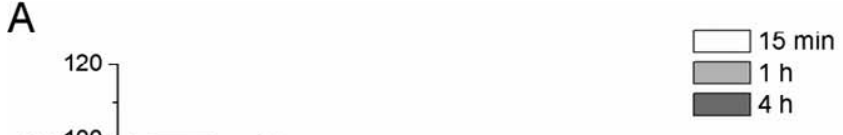

B

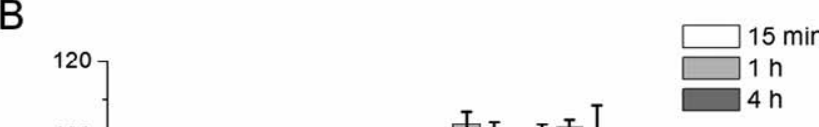

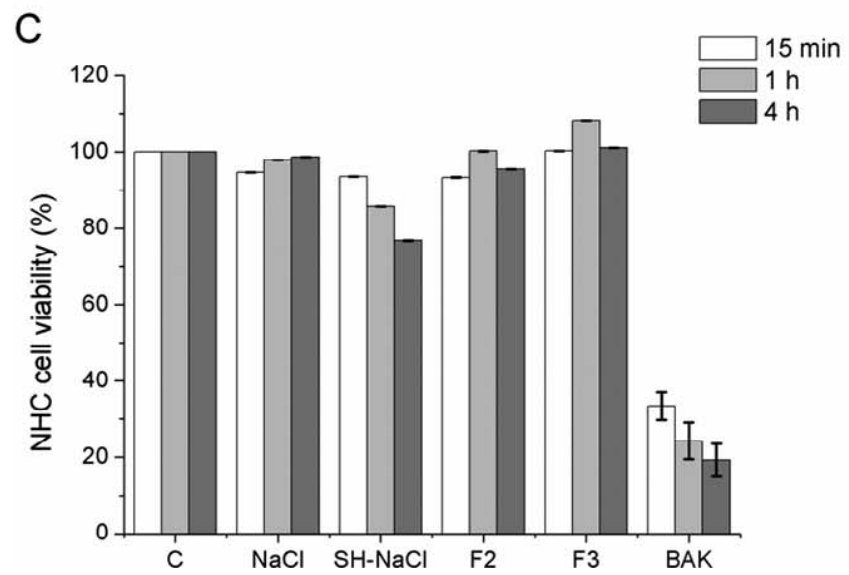

Figure 5. Cell viability of (A) RAW 264.7 macrophages, (B) HCLE cells, and (C) IOBA-NHC cells exposed to control, vehicle, and liposome formulations for 15 minutes, 1 hour, and 4 hours. (C) Untreated cells used as negative control. NaCl, $0.9 \% \mathrm{NaCl}$; SH-NaCl, $0.9 \% \mathrm{NaCl}-0.2 \% \mathrm{SH}$; $\mathrm{F} 2$, liposomes dispersed in $0.9 \% \mathrm{NaCl}(\mathrm{PC}=20 \mathrm{mg} / \mathrm{mL}) ; \mathrm{F} 3$, liposomes dispersed in $0.2 \% \mathrm{SH}-0.9 \% \mathrm{NaCl}(\mathrm{PC}=10 \mathrm{mg} / \mathrm{mL}) ; \mathrm{BAK}, 0.005 \% \mathrm{benzalkonium}$ chloride was used as the positive control. Cell viability was measured by MTT assay, results are reported as mean (\%) \pm SEM and are normalize to cell viability of untreated cells. For (C), the error bars are too small to be seen clearly.

presented signs of mucus secretion as a result of the formulation tested. These results demonstrated good in vivo tolerance of the $\mathrm{F} 3$ formulation on the OS of rabbit's eyes.

\section{Discussion}

Dry eye (DE) is characterized by alterations in the OS and by tear film instability. ${ }^{40}$ The lipid layer has an important role in tear film stability as it reduces water evaporation from the OS. Among the components of the lipid layer, the surfactant properties of phospholipids, and in particular PC, are responsible for the linkage between the lipid and aqueous layer.

In DE, the lipid layer usually is damaged and tear film instability occurs. ${ }^{41,42}$ For this reason, artificial tears that can provide lipids to the tear film are of great interest for patients suffering from DE. ${ }^{43,44}$ These formulations also can include components similar to the aqueous layer of the tear film. Moreover, the proper combination of lipids and aqueous components can behave similarly to the natural tear film. In the present work, we have designed novel ophthalmic formulations containing lipid components that are present in natural tears. Additionally, we have included a bioadhesive polymer to resemble the aqueous layer of the tear film and also to increase the residence contact time of the formulation on the OS. The liposomes composed of PC and cholesterol were dispersed in aqueous saline solutions with or without $0.2 \% \mathrm{SH}$ (F3 and F2, respectively). Vitamin E was incorporated to stabilize the lipid vesicles and prevent degradation of the fatty acids chains present in PC. From a pharmaceutical point of view, vit $\mathrm{E}$ also could provide a reparative effect on damaged os cell membranes. The potential therapeutic efficacy of the novel formulation is based on the ability to form a lipid layer that covers the OS.

The liposomal vesicles developed in this work had a size suitable for topically applied formulations and avoids any blurring of vision after instillation. ${ }^{45}$ Although a narrow liposome size distribution can be achieved easily with the help of an ultrasound probe, the use of this technological strategy has the risk of metallic particle contamination. For this reason, in this work we have used an ultrasound bath to avoid possible occurrence of metallic particles. ${ }^{46,47}$

Taking into account the chemical and physical parameters of the tears, ophthalmic formulations administered by topical route must have several technological properties. Among them, $\mathrm{pH}$, surface tension, osmolarity, and viscosity are critical in the design of formulations to be administered to a damaged OS. ${ }^{48}$ Natural tears have a physiological $\mathrm{pH}$ of approximately 7.4 and endogenous buffering capacity that reduces discomfort caused by solutions with a $\mathrm{pH}$ between 6.5 and $9 .{ }^{49,50}$ The 
corneal surface has a critical surface tension of $38 \mathrm{mN} / \mathrm{m}$ and natural tears have a surface tension in the range of 38 to 46 $\mathrm{mN} / \mathrm{m} \cdot{ }^{11,51}$ As both surface tension values are close to each other in normal eyes, tears extend homogeneously on the corneal surface, reaching a complete wetting state. However, in DE patients, tears have lower surface activity, with a surface tension of $49.6 \pm 2.2 \mathrm{mN} / \mathrm{m}$, due to the lack of lipids, proteins, and mucins. ${ }^{52,53}$

Our results showed that the surface tension of the liposomes at a PC concentration of $2.5 \mathrm{mM}$, dispersed in water (F1) and in $0.9 \% \mathrm{NaCl}$ (F2) was 27.3 and $33.7 \mathrm{mN} / \mathrm{m}$, respectively. At $25 \mathrm{mM} \mathrm{PC}$, the surface tension was 26.8 and $29.8 \mathrm{mN} / \mathrm{m}$, correspondingly. These values are lower than the critical corneal surface tension in healthy eyes and similar to the corneal epithelium surface tension in the absence of mucins that may occur in DE disease, $28 \mathrm{mN} / \mathrm{m}^{51,54}$ Thus, liposomal dispersions at concentrations of PC above $2.5 \mathrm{mM}$ will allow an adequate extension of lipids on the OS and the formation of a continuous film over the eye surface. We selected F2 and F3 liposomal formulations, with PC concentration of $20 \mathrm{mg} / \mathrm{mL}$ and $10 \mathrm{mg} / \mathrm{mL}$ respectively, to develop and characterize as artificial tears for DE.

In evaporative $\mathrm{DE}$, the loss of aqueous components of the tear film causes an increase in tear osmolarity. ${ }^{55}$ As previously reported, formulations with osmolarity values between 150 and $320 \mathrm{mOsm} / \mathrm{L}$ do not produce ocular discomfort. ${ }^{56,57}$ The $\mathrm{F} 2$ and $\mathrm{F} 3$ formulations have osmolarity values that fall within these limits. Not surprisingly, the presence of lipid vesicles produced a slight decrease in osmolarity (from 18.0 to 7.7 mOsm) after dispersion in isotonic saline. The liposomal formulation dispersed in a saline solution of $\mathrm{SH}, \mathrm{F} 3$, was physiologically iso-osmolar.

Current technology trends focus on the development of new, topically applied formulations that increase the retention time and adhesion to the OS through the use of mucoadhesive polymers, viscosity modifying agents, and penetration promoters. ${ }^{58,59}$ The $\mathrm{SH}$ used in $\mathrm{F} 3$ can exhibit non-Newtonian behavior $^{60,61}$; however, in the $\mathrm{F} 3$ formulation, the polymer displayed a Newtonian behavior. These results are a consequence of the molecular weight and the concentration of $\mathrm{SH}$ selected for our study. ${ }^{62}$

Topical formulations that exceed 20 to $40 \mathrm{mPa} \cdot \mathrm{s}$ viscosity have no additional advantages over applications with lower viscosity, because they do not uniformly mix with natural tears. ${ }^{63,64}$ Consequently, they cause difficulties during blinking and blurred vision. The discomfort causes increased blink frequency and results in more rapid removal of the ophthalmic preparation from the OS. It is critical, therefore, to find the optimal concentration of bioadhesive polymer that is capable of increasing the ocular residence time, but does not have an excessively high viscosity. Because the viscosity of natural tears is 0.3 to $8.3 \mathrm{mPa} \cdot \mathrm{s},{ }^{38,39}$ it is highly likely that $\mathrm{F} 3$, with a viscosity of $1.82 \pm 0.02 \mathrm{mPa} \cdot \mathrm{s}$, mixed uniformly, or nearly so, with the tear film. Furthermore, the presence of SH increases the contact time between the lipid vesicles and the OS through mucoadhesion mechanisms. ${ }^{65}$ An additional advantage of including $\mathrm{SH}$ in the novel artificial tear is that this polymer improves the state of the OS and enables healing and regenerative processes. ${ }^{66-68}$

In the present work, cytotoxicity studies were carried out on RAW 264.7 macrophage, HCLE, and IOBA-NHC cell lines to determine their tolerance to the liposomal formulations. The liposomal formulations F2 and F3 were well tolerated during short-, intermediate-, and long-term exposures of HCLE cells and normal conjunctival cells (IOBA-NHC) that were derived from the human OS. Taking into account the relative absence of toxicity obtained in the in vitro tolerance studies, we performed in vivo tolerance assays in rabbit eyes for the F3 liposomes containing SH. Despite differences between rabbit and human eyes in terms of tear volume, tear evaporation, and recovery time after irritant exposures, the low-volume test in rabbits usually shows a good correlation with the human experience. ${ }^{69-71}$ Our results clearly showed that the F3 formulation of liposomes with $\mathrm{SH}$ was well-tolerated by animals throughout the study period. Nevertheless, direct extrapolation from the animal results to human should be done with caution.

In summary, we have developed unpreserved formulations containing lipids intended for relieving signs and symptoms of DE disease. These formulations were composed of pharmaceutical liposomes containing amphiphilic PC, nonpolar cholesterol, and the antioxidant vit $\mathrm{E}$, all of which are natural components of the tear film. The liposomal vesicles were resuspended in aqueous solutions, and in the case of the $\mathrm{F} 3$ formulation, $\mathrm{SH}$, a bioadhesive polymer widely used in artificial tears, was added. Formulations F2 and F3 had adequate properties of $\mathrm{pH}$, osmolarity, viscosity, and surface tension to be applied topically. Both formulations were well tolerated by OS cells in vitro. In vivo studies for F3 indicated an optimal tolerance for the novel formulation in which the liposomes were suspended with the bioadhesive polymer SH. Our results supported the use of this liposomal formulation as a novel artificial tear for DE treatment. It has the potential to improve the lipid layer of the tear film by adding lipids found in the natural tears. Furthermore, the inclusion of $\mathrm{SH}$ resembles the mucin-aqueous phase of the tear film and extends the contact time of the formulation on the OS.

\section{Acknowledgments}

Supported by Spanish Grants from the Ministry of Economy and Competitiveness (FIS PI13/00516, PI13/00704; PI10/00645, and PI10/00993), UCM Research Group 920415 and RETICS RD 12/ 0034/0003.

Disclosure: M. Vicario-de-la-Torre, None; J.M. Benítez-delCastillo, None; E. Vico, None; M. Guzmán, None; B. de-lasHeras, None; R. Herrero-Vanrell, None; I.T. Molina-Martínez, None

\section{References}

1. Paulsen F. Functional anatomy and immunological interactions of ocular surface and adnexa. Dev Ophthalmol. 2008;41:2135.

2. Gipson IK. The ocular surface: the challenge to enable and protect vision: the Friedenwald lecture. Invest Ophthalmol Vis Sci. 2007;48:4391-4398.

3. Spurr-Michaud S, Argüeso P, Gipson IK. Assay of mucins in human tear fluid. Exp Eye Res. 2007;84:939-950.

4. Green-Church KB, Butovich I, Willcox M, et al. The international workshop on meibomian gland dysfunction: report of the subcommittee on tear film lipids and lipidprotein interactions in health and disease. Invest Ophthalmol Vis Sci. 2011;52:1979-1993.

5. Butovich IA. The Meibomian puzzle: combining pieces together. Prog Retin Eye Res. 2009;28:483-498.

6. Rantamaki AH, Seppanen-Laakso T, Oresic M, Jauhiainen M, Holopainen JM. Human tear fluid lipidome: from composition to function. PLoS One. 2011;6:e19553.

7. Saville JT, Zhao Z, Willcox MD, Ariyavidana MA, Blanksby SJ, Mitchell TW. Identification of phospholipids in human meibum by nano-electrospray ionisation tandem mass spectrometry. Exp Eye Res. 2010;92:238-240.

8. Ham BM, Jacob JT, Keese MM, Cole RB. Identification, quantification and comparison of major non-polar lipids in 
normal and dry eye tear lipidomes by electrospray tandem mass spectrometry. J Mass Spectrom. 2004;39:1321-1336.

9. McCulley JP, Shine W. A compositional based model for the tear film lipid layer. Trans Am Ophthalmol Soc. 1997;95:7993.

10. Rosenfeld L, Cerretani C, Leiske DL, Toney MF, Radke CJ, Fuller GG. Structural and rheological properties of meibomian lipid. Invest Ophthalmol Vis Sci. 2013;54:2720-2732.

11. Nagyová B, Tiffany, JM. Components responsible for the surface tension of human tears. Curr Eye Res. 1999;19:4-11.

12. McCulley J, Shine W. The lipid layer: the outer surface of the ocular surface tear film. Biosci Rep. 2001;21:407-418.

13. McCulley JP, Shine WE. Meibomian gland and tear film lipids: structure, function and control. Adv Exp Med Biol. 2002;506: 373-378.

14. Rosenfeld L, Fuller GG. Consequences of interfacial viscoelasticity on thin film stability. Langmuir. 2012;28:14238-14244.

15. Schuett BS, Millar TJ. Lipid component contributions to the surface activity of meibomian lipids. Invest Ophthalmol Vis Sci. 2012;53:7208-7219.

16. Millar TJ, King-Smith PE. Analysis of comparison of human meibomian lipid films and mixtures with cholesteryl esters in vitro films using high resolution color microscopy. Invest Ophthalmol Vis Sci. 2012;53:4710-4719.

17. Herok GH, Mudgil P, Millar TJ. The effect of meibomian lipids and tear proteins on evaporation rate under controlled in vitro conditions. Curr Eye Res. 2009;34:589-597.

18. Baudouin C. Detrimental effect of preservatives in eyedrops: implications for the treatment of glaucoma. Acta Ophthalmol. 2008;86:716-726.

19. Ammar D, Noecker R, Kahook M. Effects of benzalkonium chloride-preserved, polyquad-preserved, and sofZia-preserved topical glaucoma medications on human ocular epithelial cells. Adv Ther. 2010;27:837-845.

20. Baudouin C, Labbé A, Liang H, Pauly A, Brignole-Baudouin F. Preservatives in eyedrops: The good, the bad and the ugly. Prog Retin Eye Res. 2010;29:312-334.

21. Bangham AD, Standish, MM, Watkins JC. Diffusion of univalent ions across the lamellae of swollen phospholipids. $\mathrm{J} \mathrm{Mol} \mathrm{Biol}$. 1965;13:238-252.

22. Millar TJ, Tragoulias ST, Anderton PJ, et al. The surface activity of purified ocular mucin at the air-liquid interface and interactions with meibomian lipids. Cornea. 2006;25:91-100.

23. Yasueda SIK, Matsuhisa K, Terayama H, Ohtori A. Evaluation of ophthalmic suspensions using surface tension. Eur J Pharm Biopharm. 2004;57:377-382.

24. Purslow C, Wolffsohn JS. Ocular surface temperature: a review. Eye Contact Lens. 2005;31:117-123.

25. Budai L, Hajdu M, Budai M, et al. Gels and liposomes in optimized ocular drug delivery: studies on ciprofloxacin formulations. Int J Pharm. 2007;343:34-40.

26. Sechoy O, Tissie G, Sebastian C, Maurin F, Driot JY, Trinquand C. A new long acting ophthalmic formulation of carteolol containing alginic acid. Int J Pharm. 2000;207:109-116.

27. Diebold Y, Calonge M, Enríquez de Salamanca A, et al. Characterization of a spontaneously immortalized cell line (IOBA-NHC) from normal human conjunctiva. Invest Ophthalmol Visl Sci. 2003;44:4263-4274.

28. Girón N, Través P, Rodríguez B, et al. Supression of inflammatory responses by labdane-type diterpenoids. Toxicol Appl Pharmacol. 2008;228:179-189.

29. Andres-Guerrero V, Vicario-de-la-Torre M, Molina-Martinez IT, Benitez-del-Castillo JM, Garcia-Feijoo J, Herrero-Vanrell R. Comparison of the in vitro tolerance and in vivo efficacy of traditional timolol maleate eye drops versus new formulations with bioadhesive polymers. Invest Ophthalmol Vis Sci. 2011; 52:3548-3556.

30. Scudiero DA, Shoemaker RH, Paul KP, et al. Evaluation of a soluble tetrazolium/formazan assay for cell growth and drug sensitivity in culture using human and other tumor cell lines. Cancer Res. 1988;4827-4833.

31. Liu Y, Peterson DA, Kimura H, Schubert D. Mechanism of cellular 3-(4,5-dimethylthiazol-2-yl)-2,5-diphenyltetrazolium bromide (MTT) reduction. J Neurochem. 1997;69:581-593.

32. Saarinen-Savolainen P, Järvinen T, Araki-Sasaki K, Watanabe H, Urtti A. Evaluation of cytotoxicity of various ophthalmic drugs, eye drop excipients and cyclodextrins in an immortalized human corneal epithelial cell line. Pharm Res. 1998;15:12751280.

33. Pellinen P, Huhtala A, Tolonen A, Lokkila J, Maenpaa J, Uusitalo $\mathrm{H}$. The cytotoxic effects of preserved and preservative-free prostaglandin analogs on human corneal and conjunctival epithelium in vitro and the distribution of benzalkonium chloride homologs in ocular surface tissues in vivo. Curr Eye Res. 2012;37:145-154.

34. Seibold LK, Ammar DA, Kahook MY. Acute effects of glaucoma medications and benzalkonium chloride on pre-adipocyte proliferation and adipocyte cytotoxicity in vitro. Curr Eye Res. 2012;38:70-74.

35. Enríquez de Salamanca A, Diebold Y, Calonge M, et al. Chitosan nanoparticles as a potential drug delivery system for the ocular surface: toxicity, uptake mechanism and in vivo tolerance. Invest Ophthalmol Vis Sci. 2006;47:1416-1425.

36. Takeuchi H, Yamamoto H, Toyoda T, Toyobuku H, Hino T, Kawashima Y. Physical stability of size controlled small unilameller liposomes coated with a modified polyvinyl alcohol. Int J Pharm. 1998;164:103-111.

37. Lasic DD. Novel applications of liposomes. Trends Biotechnol. 1998;16:307-321.

38. Yamaguchi M, Ueda K, Isowaki $A$, et al. Mucoadhesive properties of chitosan-coated ophthalmic lipid emulsion containing indomethacin in tear fluid. Biol Pharm Bull. 2009;32:1266-1271.

39. Tiffany JM. The viscosity of human tears. Int Ophthalmol. 1991;15:371-376.

40. Lemp MA, Baudouin $\mathrm{C}$, Baum $\mathrm{J}$, et al. The definition and classification of dry eye disease: report of the Definition and Classification Subcommittee of the International Dry Eye WorkShop (2007). Ocul Surf.2007;5:75-92.

41. Sweeney DF, Millar TJ, Raju SR. Tear film stability: a review. Exp Eye Res. 2013;117:28-38.

42. Gipson IK. Age-related changes and diseases of the ocular surface and cornea. Invest Ophthalmol Vis Sci. 2013;54: ORSF48-53.

43. Calonge M. The treatment of dry eye. Surv Ophthalmol. 2001; 45:S227-S239.

44. Lee SY, Tong L. Lipid-containing lubricants for dry eye: a systematic review. Optom Vis Sci. 2012;89:1654-1661.

45. Hecht G. Ophthalmic preparations. In: University of Sciences in Philadelphia, ed. Remington: The Science and Practice of Pharmacy. Philadelphia, PA: Lippincott, Williams \& Wilkins; 2001:821-833.

46. Samad A, Sultana Y, Aqil M. Liposomal drug delivery systems: an update review. Curr Drug Deliv. 2007;4:297-305.

47. Berger N, Sachse A, Bender J, Schubert R, Brandl M. Filter extrusion of liposomes using different devices: comparison of liposome size, encapsulation efficiency, and process characteristics. Int J Pharm. 2001;31:55-68.

48. Baeyens V, Gurny R. Chemical and physical parameters of tears relevant for the design of ocular drug delivery formulations. Pharm Acta Helv. 1997;72:191-202. 
49. Carney LG, Mauger TF, Hill RM. Buffering in human tears: $\mathrm{pH}$ responses to acid and base challenge. Invest Ophthalmol Vis Sci. 1989;30:747-754.

50. Yamada M, Kawai M, Mochizuki H, Hata Y, Mashima Y. Fluorophotometric measurement of the buffering action of human tears in vivo. Curr Eye Res. 1998;17:1005-1009.

51. Holly FJ, Lemp MA. Wettability and wetting of corneal epithelium. Exp Eye Res. 1971;11:239-250.

52. Tiffany JM. Tears in health and disease. Eye. 2003;17:923-926.

53. Bron AJ, Tiffany JM, Gouveia SM, Yokoi N, Voon LW. Functional aspects of the tear film lipid layer. Exp Eye Res. 2004;78:347360.

54. Glasgow BJ, Marshall G, Gasymov OK, Abduragimov AR, Yusifov TN, Knobler CM. Tear lipocalins: potential lipid scavengers for the corneal surface. Invest Ophthalmol Vis Sci. 1999; 40:3100-3107.

55. Mantelli F, Massaro-Giordano M, Macchi I, Lambiase A, Bonini $\mathrm{S}$. The cellular mechanisms of dry eye: from pathogenesis to treatment. J Cell Physiol. 2013;228:2253-2256.

56. Tomlinson A, Khanal S, Ramaesh K, Diaper C, McFadyen A. Tear film osmolarity: determination of a referent for dry eye diagnosis. Invest Ophthalmol Vis Sci. 2006;47:4309-4315.

57. Gary NF. The correlation between the tear film lipid layer and dry eye disease. Surv Ophthalmol. 2007;52:369-374.

58. Ludwig A. The use of mucoadhesive polymers in ocular drug delivery. Adv Drug Deliv Rev. 2005;57:1595-1639.

59. Kaur IP, Garg A, Singla AK, Aggarwal D. Vesicular systems in ocular drug delivery: an overview. Int J Pharm. 2004;269:114.

60. Prieto JG, Pulido MM, Zapico J, et al. Comparative study of hyaluronic derivatives: rheological behaviour, mechanical and chemical degradation. Int J Biol Macromol. 2005;35:63-69.
61. Falcone SJ, Palmeri DM, Berg RA. Rheological and cohesive properties of hyaluronic acid. J Biomed Mater Res A. 2006; 76A:721-728.

62. Chong BF, Blank LM, McLaughlin R, Nielsen LK. Microbial hyaluronic acid production. Appl Microbiol Biotechnol. 2005; 66:341-351.

63. Akram M, Shyum S, Gauhar S. Development of new ophthalmic suspension prednisolone acetate 1\%. PakJ Pharm Sci. 2010;23:149-154.

64. Gan L, Han S, Shen J, et al. Self-assembled liquid crystalline nanoparticles as a novel ophthalmic delivery system for dexamethasone: improving preocular retention and ocular bioavailability. Inter J Pharm. 2010;396:179-187.

65. Bravo-Osuna I, Noiray M, Briand E, et al. Interfacial interaction between transmembrane ocular mucins and adhesive polymers and dendrimers analyzed by surface plasmon resonance. Pharm Res. 2012;29:2329-2340.

66. Nakamura S, Okada S, Umeda Y, Saito F. Development of a rabbit model of tear film instability and evaluation of viscosity of artificial tear preparations. Cornea. 2004;23:390-397.

67. Park Y, Cho S, Linhardt RJ. Exploration of the action pattern of Streptomyces hyaluronate lyase using high-resolution capillary electrophoresis. Biochim Biophys Acta. 1997;1337:217-226.

68. Jedrzejas, JM, Mello LV, de Groot BL, Li S. Mechanism of hyaluronan degradation by streptococcus pneumoniae hyaluronate lyase. J Biol Chem. 2002;277:28287-28297.

69. Freeberg FE, Nixon GA, Reer PJ, et al. Human and rabbit eye responses to chemical insult. Fundam Appl Toxicol. 1986;7: 626-634.

70. Walker AP. A more realistic animal technique for predicting human eye response. Food Chem Toxicol. 1985;23:175-178.

71. Lambert LA, Chambers WA, Green S, et al. The use of lowvolume dosing in the eye irritation test. Food Chem Toxicol. 1993;31:99-103. 